\title{
Efficiency of back muscles training and balance therapy in rehabilitation of patients with osteoporotic vertebral fractures
}

\author{
Larisa A Marchenkova (1), Ekaterina V Makarova (2), Mikhail A Eryomushkin (3), \\ Anatoly D Fesun (4), Elena M Styazkina (5), Ekaterina I Chesnikova (5)
}

(1) Somatic rehabilitation, anti-aging and reproductive health department at National Medical Research Center of Rehabilitation and Balneology Moscow, Russia; (2) N.A. Semashko National Research Institute of Public Health, Moscow, Russia; (3) Physical therapy and clinical biomechanics department, Orthopedics, biomechanics, kinesiotherapy and manual therapy department at National Medical Research Center for Rehabilitation and Balneology Moscow, Russia; (4) National Medical Research Center of Rehabilitation and Balnology, Moscow, Russia; (5) Physical therapy and clinical biomechanics department at National Medical Research Center of Rehabilitation and Balneology, Moscow, Russia.

This article is distributed under the terms of the Creative Commons Attribution Noncommercial License (CC BY-NC 4.0) which permits any noncommercial use, distribution, and reproduction in any medium, provided the original author(s) and source are credited.

\begin{abstract}
Medical rehabilitation of patients with osteoporotic vertebral fractures (VF) remains an insufficiently developed topic and requires additional research. Aim of the study was to assess the efficiency of back muscles training and balance therapy in rehabilitation of patients with osteoporotic vertebral fractures. Prospective, interventional, open-label, controlled study in two parallel groups, performed in inpatient department settings at "National Medical Research Center of Rehabilitation and Balneology” during 2018. The study involved 120 patients (11 men and 109 women) aged 40-80 (mean age 65.4 \pm 9.1 years) who were admitted for medical rehabilitation for systemic OP and VF. The rehabilitation program in the main group included: 1) Mechanotherapy on the Back-Therapy-Center Dr. Wolf complex with biofeedback (Germany); 2) Balance therapy on a double unstable COBS platform, with biofeedback (Germany); 3) Hydrokinesiotherapy in a pool; 4) Gymnastic exercises (Gorinevskaya-Dreving method). Results. The use of the three-week program of physical rehabilitation using mechanotherapy, balance therapy and special complexes of physiotherapy exercises in the gym and in the pool in patients with osteoporotic VF significantly increases the strength of the muscle corset, helps to eliminate the existing muscle deficit in TE and TF and results in a more physiological distribution of the strength ratio between TE and TF. The rehabilitation program improves the function of static and dynamic balance, both with closed and open eyes, which can be observed in the return of the center of gravity to a physiological position and in improved reaction speed to changes in body position. Usage of mechanotherapeutic methods in rehabilitation of patients with osteoporotic VF is effective for basic motor function improvement and disability reduction.
\end{abstract}

Key Words: Rehabilitation; osteoporotic vertebral fractures; mechanotherapy; kinesiotherapy; hydrotherapy; balance; muscle strength; physical therapy.

Eur J Transl Myol 31 (4): 9945, 2021 doi: 10.4081/ejtm.2021.9945

Osteoporosis (OP) is a systemic skeletal disease characterized by decreased bone strength and increased risk of fracture with even a minor injury. ${ }^{1}$ Fractures play a major role in the medical and social significance of OP, the most severe being fractures of femur, humerus, pelvic bones, as well as compression fractures of the vertebrae, which entail a significant decrease in the quality of life (QOL), disability and increased mortality. ${ }^{1-3}$ Osteoporotic vertebral fractures (VF) often remain without timely diagnosis, treatment and rehabilitation, and therefore require special attention from clinicians. Clinically, VF are associated with intense back pain, pathological spinal deformities, loss of height, functional and motor limitations, impaired coordination, increased risk of falls and recurrent fractures, as well as decreased social activity and worsening of overall quality of life. ${ }^{4}$ Thus, medical rehabilitation is essential for this group of patients. Rehabilitation measures are of special importance, gradually expanding physical capabilities, 
providing specific, safe and sufficiently intense exercise. ${ }^{5}$ Rehabilitation measures are aimed at restoring impaired functions and preventing possible complications. It has been proven that the basis of medical rehabilitation programs for patients with osteoporotic VF should be different types of physical therapy and exercise regimens. ${ }^{6,7}$ In clinical practice, the most rational and effective approach lies in combining several types of exercises instead of just using one type. However, there are still very few works related to comprehensive rehabilitation programs for people with osteoporotic VF. The data are heterogeneous and there is no clear understanding of the benefits of any method in patients with VF associated with OP. There are no clear clinical guidelines on managing these patients. $^{8}$ Thus, improvement of medical rehabilitation programs for patients with osteoporotic VF remains an insufficiently developed topic and requires additional research. ${ }^{9}$ In this regard, we carried out work aimed at scientifically substantiating the effectiveness of a rehabilitation program using mechanotherapy methods with biofeedback and special complexes of physiotherapy exercises in patients with osteoporotic VF.

\section{Materials and Methods}

The design was a prospective, interventional, open-label, controlled study in two parallel groups. The study was conducted in the "National medical research center of rehabilitation and balneology" (Russia, Moscow) during the period of 2018 year. The study involved 120 patients (11 men and 109 women) aged 40-80 (mean age 65.4 \pm 9.1 years) who were admitted for medical rehabilitation for systemic OP and VFs (Figure 1). Inclusion criteria: at least one pathological compression VF according to the criteria of H. Genant, ${ }^{10}$ confirmed by X-ray and not more than 12 months old; indicators of bone mineral density (BMD) $<-2.0$ according to the T-criterion in the L1-L4 lumbar segment of the spine or in the proximal femur. The exclusion criteria were the refusal (or inability) of the patient to sign a voluntary informed consent to participate in the study, age under 40, pregnancy, lactation, cachexia of any origin, diseases or drug therapy that adversely affect motor abilities and muscle strength. The patients were randomized into two groups by simple randomization in a $1: 1$ ratio in to study $(n=60)$ and control $(n=60)$ groups with the help of "Randomizer for clinical trials” iOS app.

1) Clinical examination and anamnesis collection, followed by BMI calculation and absolute 10-year fracture risk according to FRAX

2) Study of the isometric strength of the trunk muscles using the tenzodynamometry method on the BackCheck Sports \& Prevention diagnostic unit, Dr. Wolf, Germany. The strength of the trunk flexors (TF), trunk extensors (TE), left (LLF) and right lateral flexors (RLF) was studied. The device evaluated the absolute muscle strength in $\mathrm{kg}$ and its recommended values for a specific gender, age and weight.

3) Balance function investigation (stabilometry on "Stabilan” platform, OKB "Ritm", Russia). The method uses the European position with eyes closed and eyes open.

Stabilometry devices record the main postural characteristics based on the coordinates of the center of pressure (CP) in dynamics in the plane of support.

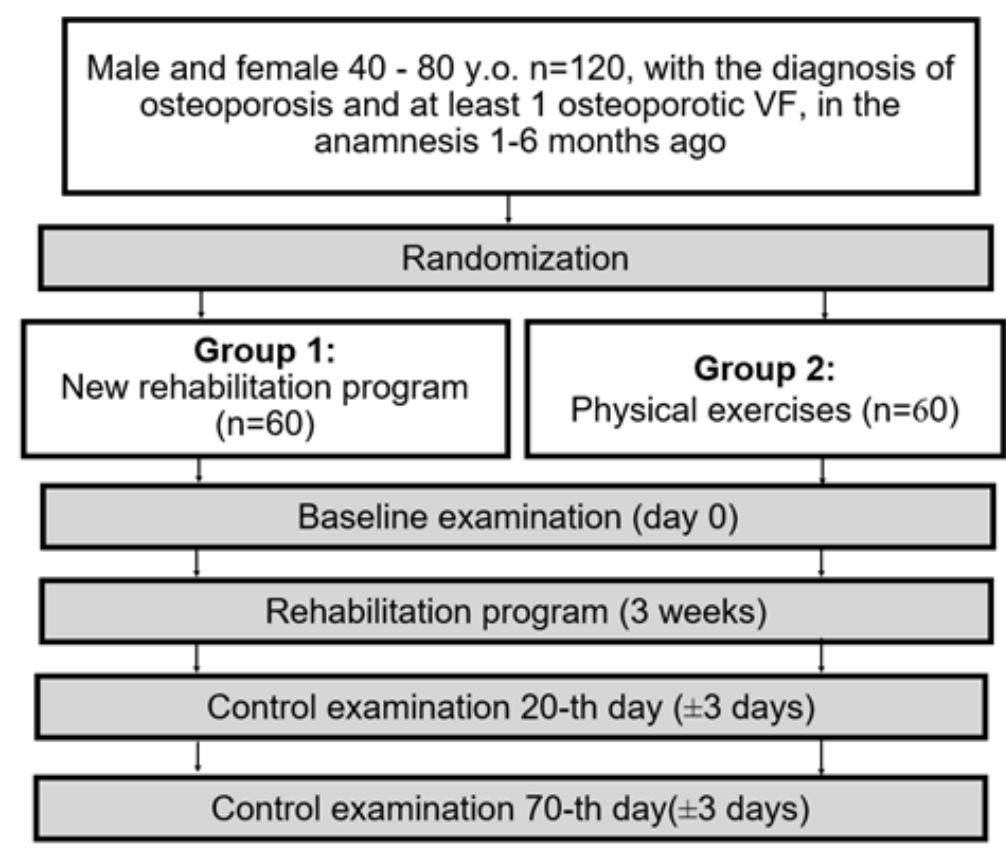

Fig 1. Study design; y.o. - year old 
Rehabilitation after osteoporotic vertebral fractures

Eur J Transl Myol 31 (4): 9945, 2021 doi: 10.4081/ejtm.2021.9945

\begin{tabular}{|c|c|c|c|}
\hline Observed indicators & Main group $(\mathrm{n}=60)$ & Control group $(\mathrm{n}=60)$ & $p$ \\
\hline Age (years) & $65.4 \pm 7.1$ & $65.5 \pm 7.8$ & 0.94 \\
\hline Weight (kg) & $74.8 \pm 14.2$ & $75.9 \pm 13.2$ & 0.16 \\
\hline Hight (cm) & $161.3 \pm 16.3$ & $160.5 \pm 11.6$ & 0.12 \\
\hline BMI (kg/m2) & $26.7 \pm 4.3$ & $27.1 \pm 6.2$ & 0.74 \\
\hline VFs number (n) & $2.0[1.0 ; 9.0]$ & $2.0[1.0 ; 7.0]$ & 0.43 \\
\hline General fracture risk FRAX (\%) & $23.0[17.5 ; 28.0]$ & $20.4[11.3 ; 25.0]$ & 0.15 \\
\hline Hip fracture risk FRAX (\%) & 6.9 [3.6;9.3] & $5.1[2.2 ; 7.9]$ & 0.56 \\
\hline BMD L1-L4 (g/cm) & $0.859 \pm 0.13$ & $0.949 \pm 0.29$ & 0.14 \\
\hline BMD left femoral neck (g/cm) & $0.733 \pm 0.09$ & $0.730 \pm 0.142$ & 0.93 \\
\hline T-score L1-L4 (SD) & $-2.5 \pm 0.86$ & $-2.2 \pm 1.5$ & 0.77 \\
\hline T- score left femoral neck (SD) & $-2.1 \pm 0.57$ & $-2.0 \pm 0.84$ & 0.93 \\
\hline
\end{tabular}

Tensodinamometry and stabilometry tests were carried out in patients in both groups in dynamics after the completion of rehabilitation, as well as in the end of one month of follow-up after the end of the rehabilitation course. There was no difference between the groups at the baseline (Table 1).

The rehabilitation program in the main group included: 1) Mechanotherapy on the Back-Therapy-Center Dr. Wolf complex with biofeedback (Sports \& Prevention GmbH, Germany), \#10 with an instructor, 20-30 minutes. 2) Interactive sensorimotor training (balance therapy) on a double unstable KOBS platform (coordination, balance, strength) with biofeedback (Physiomed Elektromedizin AG), \#15 with an instructor, 10-15 minutes. 3) Hydrokinesiotherapy was carried out in a specially equipped pool with fresh water, temperature $28-30{ }^{\circ} \mathrm{C}$, \#15 with an instructor in a group, 30-40 minutes. 4) Gymnastic exercises (Gorinevskaya-Dreving method) in the gym, in a group, \#15 with an instructor, 40 minutes. The technique was modified for patients with osteoporosis without an emphasis on active hyperextension).

Statistical analysis was performed using Microsoft Statistica 10.0 software using parametric and nonparametric methods. The values were presented as the mean and standard deviation $\mathrm{M} \pm \mathrm{m}$ with normal distribution, or as the median and the 25th and 75th quartiles of $\mathrm{Me}$ [25\%; 75\%], if it is not normal. For pairwise comparisons of indicators in independent samples, Student's t-test or Mann-Whitney test with Bonferroni's correction was used. To compare values in dependent samples, the Wilcoxon test or Student's t-test was used. When testing statistical hypotheses, the critical significance level was taken equal to 0.05 .

\section{Results}

Both groups shown dynamics in tests taken immediately after the end of the rehabilitation procedures. However, it was more pronounced among patients receiving an intensive rehabilitation program (Figure. 2).

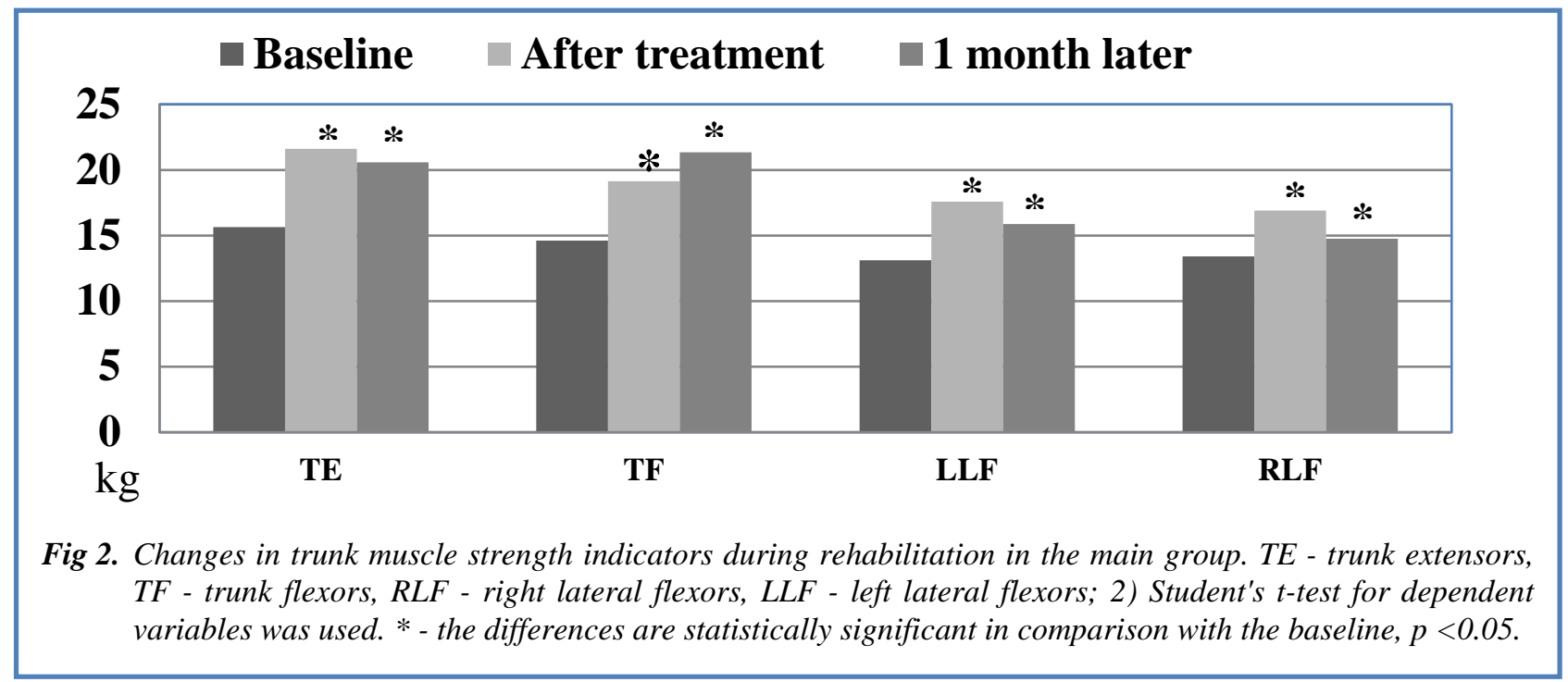


Table 2. Dynamics of muscle strength indicators according to tensodinamometry data against the background of a rehabilitation course

\begin{tabular}{|l|l|c|c|}
\hline \multirow{2}{*}{$\begin{array}{l}\text { Observed } \\
\text { indicators }\end{array}$} & Stage & \multicolumn{2}{|c|}{ Studied groups } \\
\cline { 2 - 4 } & & Main group & Control group \\
\hline \multirow{2}{*}{$\begin{array}{l}\text { TE (deficit of } \\
\text { strength \%) }\end{array}$} & Baseline & $-40.9[-82.4 ; 1.3]$ & $-39.2[-79.5 ; 2.1]$ \\
\cline { 2 - 4 } & After treatment & $-15.9[-49.7 ; 26.4] \dagger$ & $-19.5[-41.7 ; 19.6] \dagger$ \\
\cline { 2 - 4 } & 1 month later & $-18.8[-52.9 ; 23.2] \dagger *$ & $-37.1[-66.0 ;-7.8]$ \\
\hline \multirow{2}{*}{$\begin{array}{l}\text { TF (deficit of } \\
\text { strength \%) }\end{array}$} & Baseline & $-18.1[-71.4 ;-24.1]$ & $-14.4[-66.3 ;-20.2]$ \\
\cline { 2 - 4 } & After treatment & $+8.7[24.7 ; 63.5] \dagger *$ & $-1.1[-42.3 ; 48.4] \dagger$ \\
\cline { 2 - 4 } & 1 month later & $+17.3[28.6 ; 80.2] \dagger *$ & $-13.5[-30.1 ; 23.6]$ \\
\hline \multirow{2}{*}{$\begin{array}{l}\text { LLF (deficit of } \\
\text { strength \%) }\end{array}$} & Baseline & $-8.2[-32.5 ; 1.8]$ & $-10.3[-27.2 ;-1.7]$ \\
\cline { 2 - 4 } & After treatment & $-5.2[-18.5 ; 10.1] \dagger$ & $-6.03[-19.1 ; 0.6]$ \\
\cline { 2 - 4 } & 1 month later & $-7.0[-21.3 ;-2.5] \dagger$ & $-12.3[-19.7 ;-3.1]$ \\
\hline \multirow{2}{*}{$\begin{array}{l}\text { RLF (deficit of } \\
\text { strength \%) }\end{array}$} & Baseline & $-8.4[-22.3 ; 6.1]$ & $-8.01[-20.5 ; 5.8]$ \\
\cline { 2 - 4 } & After treatment & $-6.8[-12.8 ; 6.9] \dagger$ & $-7.33[-10.6 ; 6.3]$ \\
\cline { 2 - 4 } & 1 month later & $-7.9[-19.3 ; 5.2] \dagger$ & $-10.05[-23.7 ; 3.0]$ \\
\hline
\end{tabular}

The data are presented as Me [Q1;Q3]. The Wilcoxon test was used to compare the values. $\dagger$ - differences from baseline; * - differences in comparison with group 2, $p<0.05$.

After the end of the course in the main group, the strength of BE muscles increased to $21.7 \pm 10.1 \mathrm{~kg}(\Delta+5.9 \pm 3.0$, $\mathrm{p}<0.001)$, TF increased to $18.9 \pm 8.2 \mathrm{~kg}(\Delta+4.3 \pm 1.3$, $\mathrm{p}<0.001), \mathrm{LLF}-$ to $17.5 \pm 6.6(\Delta+4.4 \pm 2.4, \mathrm{p}<0,001)$, and RLF to $17.8 \pm 7.2 \mathrm{~kg}(\Delta+4.4 \pm 1.8, \mathrm{p}<0.001)$ (Figure 2). At the same time, the deficit of muscle strength decreased in TE to $-15.8[-49.7 ; 26.4] \%(\mathrm{p}<0.001)$ and in TF to +8.7 [24.7;63.5] $(\mathrm{p}<0.001)$, but did not changed significantly in LLF ( $\mathrm{p}=0.53)$ and RLF $(\mathrm{p}=0.50)$ (Table 2).

In the control group, immediately after the end of treatment, there was an increase in the strength of $\mathrm{BE}$ to $17.0 \pm 11.0 \mathrm{~kg}(\Delta+1.9 \pm 3.6, \mathrm{p}=0.03)$ and $\mathrm{BF}$ to $16.2 \pm$
$8.9 \mathrm{~kg}(\Delta+0.32 \pm 2.1, \mathrm{p}=0.02), \operatorname{LLF}(14.98 \pm 6.91 \mathrm{~kg}$, $\mathrm{p}=0.19)$ and $\operatorname{RLF}(15.30 \pm 7.01 \mathrm{~kg}, \mathrm{p}=0.2)$. The deficit of strength in BE and BF significantly decreased (Table 2). Indicators of BF and LLF strength in the study groups after the completion of rehabilitation significantly differed ( $p=0.03$ and 0.04 , respectively).

One month after the end of the program, the achieved rehabilitation effect remained in the main study group: the strength of TE was $20.5 \pm 7.7 \mathrm{~kg}$ ( $\mathrm{p}=0.000$ compared to the values before treatment, $\mathrm{p}=0.56$ compared to the values after the end of therapy), TF $=20.2 \pm 8.3 \mathrm{~kg}$ (p $<0.001$ and $p=0.26$, respectively), $\mathrm{LLF}=15.6 \pm 5.1 \mathrm{~kg}$

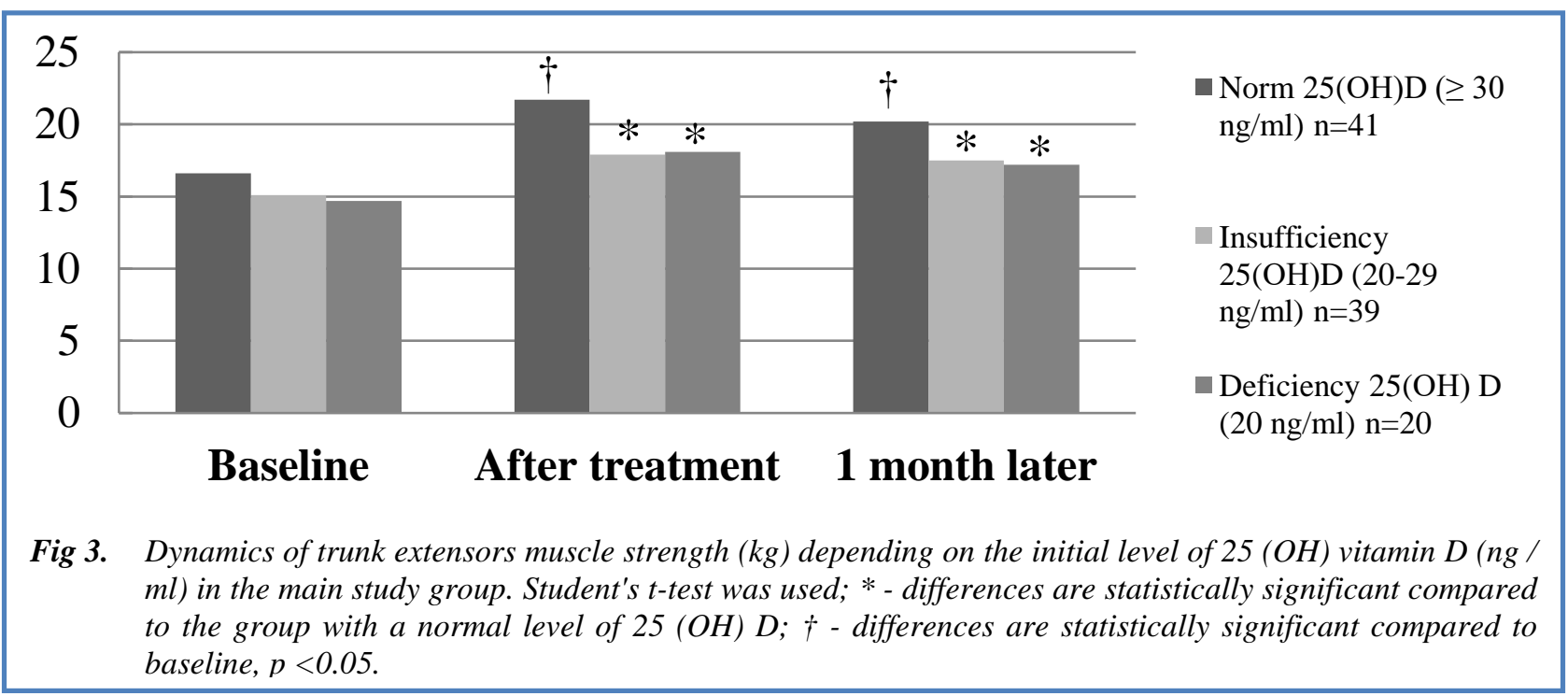




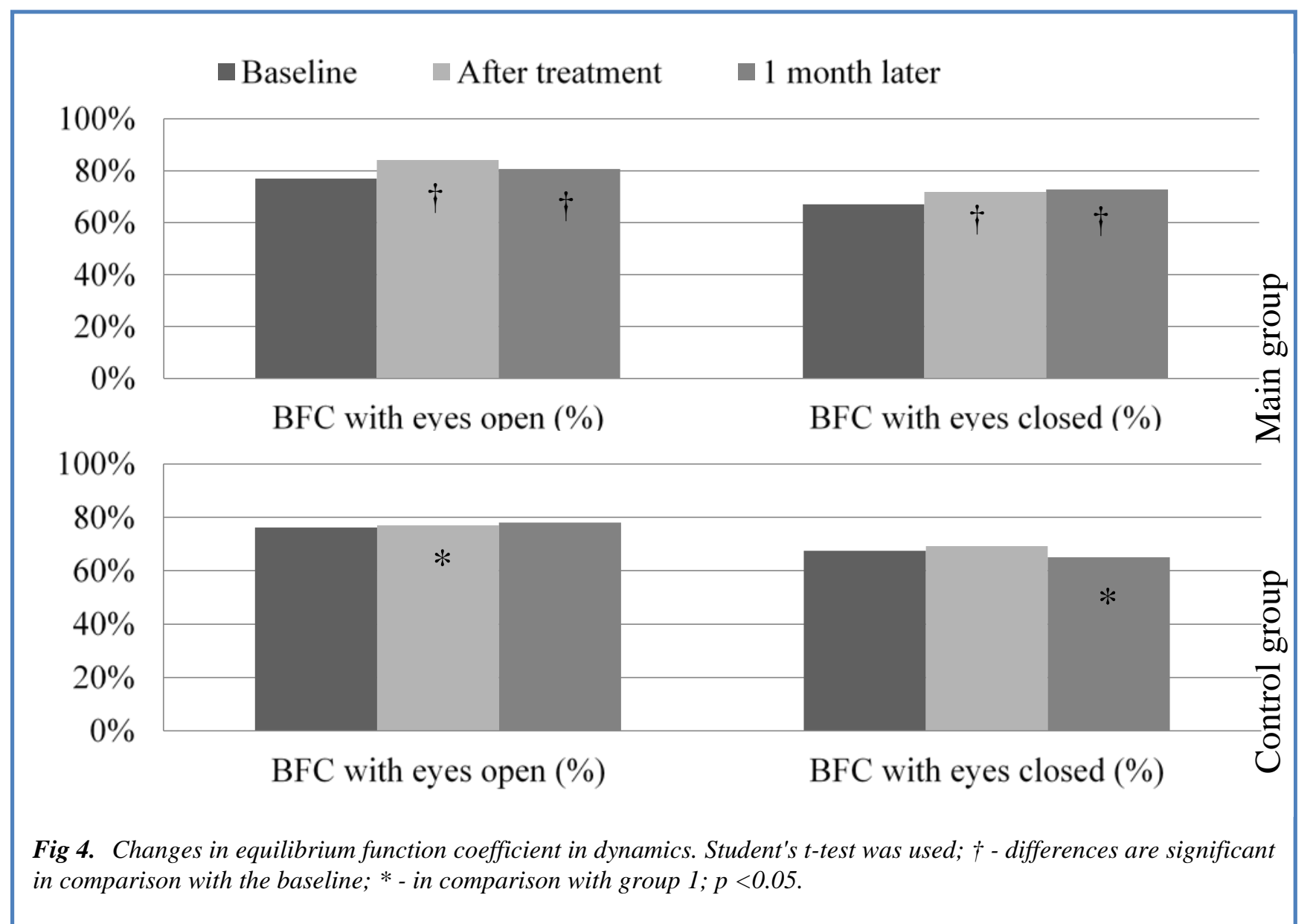

( $\mathrm{p}=0.007$ and $\mathrm{p}=0.06$, respectively), $\mathrm{RLF}=16.6 \pm 5.5$ $\mathrm{kg}(\mathrm{p}=0.002$ and $\mathrm{p}=0.26$, respectively). The muscle strength deficit did not increase one month after the end of therapy ( $\mathrm{p}>0.05$ ), see Figure 2 and Table 2.

As presented in the Figure 3, patients with a normal level of 25-OH vitamin D had better indicators of BE muscle strength after the rehabilitation course $(21.7 \mathrm{~kg})$ and one month after the end of treatment $(20.2 \mathrm{~kg})$, in comparison with the group with deficiency $(17.9 \mathrm{~kg}, \mathrm{p}=0.0008$ and $17.5 \mathrm{~kg}, \mathrm{p}=0.005)$ and vitamin D deficiency $(18.1 \mathrm{~kg}, \mathrm{p}$ $=0.0009$ and $17.2 \mathrm{~kg}, \mathrm{p}=0.003$ ).

When conducting stabilometry immediately after the end of the course in the main and control groups, improvements in the balance function coefficient (BFC) were registered with eyes open (from $77.0 \pm 7.6$ to 84.1 $\pm 8.6 \%, p=0.003$, and from $76.2 \pm 11.9$ to $77.0 \pm 11.9 \%$, p> 0.05, respectively) and eyes closed (from $67.1 \pm 9.7$ to $73.8 \pm 9.6 \%, p=0.009$, and from $67.5 \pm 15.3$ to 69.2 $\pm 15.5, \mathrm{p}>0.05$, respectively). When compared with the control group immediately after the end of therapy, the main group had significantly higher BFC values with eyes open ( $p=0.007)$, Figure 4 .

Other observed changes: a decrease in the frontal displacement $(p=0.006$ and $p=0.001)$, a decrease of the statokinesiogram (SCG) area $(\mathrm{p}=0.04$ and $\mathrm{p}=0.05)$, an increase in the speed of movement of the pressure center $(\mathrm{PC})(\mathrm{p}=0.001$ and $\mathrm{p}=0.05)$, Tables 3 and 4 .
One month after the end of the rehabilitation course, the main study group retained the positive effect of rehabilitation according to stabilometric indicators and coordination ability tests. In comparison with the baseline, the following parameters were significantly higher: BFC with eyes open $(80.7 \pm 9.1 \% \mathrm{p}=0.007)$ and eyes closed $(72.0 \pm 10.3 \%, p=0.034)$ (Figure 4$)$, speed of movement of the PC, reliably lower frontal displacement and smaller SCG area.

The difference between the stabilometry values after the end of the course and one month later was insignificant ( $>0.05$ ), which indicates the stability of the achieved effect. In comparison with the main group, the control group had inferior stabilometry values in the following indicators: BFC with eyes closed $(65.0 \pm 9.7 \%, \mathrm{p}=$ 0.003) (Fig.4), frontal displacement, speed of movement of the PC; SCG area (Tables 3 and 4).

\section{Discussion}

Rehabilitation and restorative medicine is actively developing worldwide. ${ }^{11}$ Along with the introduction of increasingly advanced techniques, the development of high-tech equipment and overall scientific progress, new methods appear for the prevention and early treatment of various diseases, restoration of the patient's functional capabilities and quality of life. ${ }^{12,13}$ Compression VF in patients with OP are associated with functional and motor 


\begin{tabular}{|l|l|c|c|}
\hline \multirow{2}{*}{ Table 3. Dynamics of stabilometric indicators (1) } \\
\hline \multirow{3}{*}{ Parameter } & \multicolumn{2}{|c|}{ Stage } & \multicolumn{2}{c|}{ Studied groups } \\
\cline { 2 - 4 } & & Main group (n=60) & Control group (n=60) \\
\hline \multirow{3}{*}{$\begin{array}{l}\text { Frontal displacement } \\
(\mathrm{mm})\end{array}$} & Baseline & $3.7[1.0 ; 6.8]$ & $4.1[2.7 ; 4.9]$ \\
\cline { 2 - 4 } & After treatment & $1.9[0.7 ; 2.4] \dagger$ & $2.1[1.9 ; 5.2] \dagger$ \\
\cline { 2 - 4 } & 1 month later & $2.6[1.5 ; 3.3] \dagger *$ & $4.5[3.0 ; 5.9]$ \\
\hline \multirow{3}{*}{$\begin{array}{l}\text { Sagittal displacement } \\
(\mathrm{mm})\end{array}$} & Baseline & $6.8[3.1 ; 17.3]$ & $6.9[2.5 ; 14.4]$ \\
\cline { 2 - 4 } & After treatment & $4.6[5.1 ; 10.1]$ & $5.3[4.0 ; 12.2]$ \\
\cline { 2 - 4 } $\begin{array}{l}\text { Frontal deviation } \\
(\mathrm{mm})\end{array}$ & 1 month later & $5.6[3.2 ; 14.1]$ & $5.3[3.8 ; 14.9]$ \\
\cline { 2 - 4 } & Baseline & $1.0[-1.1 ; 1.3]$ & $1.0[-1.1 ; 2.1]$ \\
\cline { 2 - 4 } & After treatment & $1.0[1.2 ; 1.8]$ & $1.2[-1.2 ; 2.8]$ \\
\cline { 2 - 4 } & 1 month later & $1.1[1.2 ; 1.9]$ & $1.07[-1 ; 2.4]$ \\
\hline \multirow{3}{*}{$\begin{array}{l}\text { Sagittal deviation } \\
\text { (mm) }\end{array}$} & Baseline & $1.2[-1.0 ; 1.7]$ & $1.1[0.9 ; 2.2]$ \\
\cline { 2 - 4 } & After treatment & $1.1[1.1 ; 1.7]$ & $1.0[0.8 ; 2.0]$ \\
\cline { 2 - 4 } & 1 month later & $1.0[1.1 ; 1.8]$ & $1.0[0.9 ; 2.1]$ \\
\hline
\end{tabular}

Data are presented as Me [Q1; Q3]. The Wilcoxon test was used to compare the values, $\dagger$ - differences compared to the baseline; * - compared to group 2, $p<0.05$.

limitations, which is a direct indication for medical rehabilitation. ${ }^{14}$ Given the pathological fragility of the bone and the risk of new fractures, physical therapy in this group of patients should be specialized. ${ }^{15,16}$ The topic of physical exercises in patients with OP is covered well in the specialized literature. Generally accepted recommendations regarding physical activity are included in clinical guidelines for OP in many countries. ${ }^{2,4,17,18}$ Physical activity slows down bone resorption, increases muscle strength, improves static and dynamic balance, which is associated with decreased risk of falls and new fractures, preservation of somatic wellbeing, and increased social and physical activity. ${ }^{17-20}$ The Russian guidelines for the management of patients with OP describe two types of recommended exercises: with static and dynamic body weight load and resistance exercises). ${ }^{13}$

Modern mechanotherapy systems can be used for rehabilitation in this group of patients. They allow for training of deep back muscles, which should help stabilize the vertebrae, strengthen the "muscle corset", relieve muscle spasms and reduce pain. The effect of mechanotherapy is more intense and specific in comparison with therapeutic gymnastics complexes, which makes it possible to achieve faster and better results, shorten the period of rehabilitation, increase patient satisfaction and adherence to therapy. ${ }^{21,22}$ Biofeedback in mechanotherapy systems can reduce the frequency of adverse events. Dosed load prevents overstrain, and condition monitoring allows the specialist

\begin{tabular}{|c|c|c|c|}
\hline \multicolumn{4}{|c|}{ Table 4. Dynamics of stabilometric indicators (2) } \\
\hline \multirow[t]{2}{*}{ Parameter } & \multirow[t]{2}{*}{ Stage } & \multicolumn{2}{|c|}{ Studied groups } \\
\hline & & Main group & Control group \\
\hline \multirow{3}{*}{$\begin{array}{l}\text { PC movement speed } \\
(\mathrm{mm} / \mathrm{s})\end{array}$} & Baseline & $9.5 \pm 3.4$ & $9.2 \pm 4.0$ \\
\hline & After treatment & $12.2 \pm 3.0 \dagger$ & $10.1 \pm 3.9 \dagger$ \\
\hline & 1 month later & $11.3 \pm 3.6 \dagger *$ & $9.9 \pm 4.5$ \\
\hline \multirow[t]{3}{*}{ SCG area $\left(\mathrm{mm}^{2}\right)$} & Baseline & $176.8 \pm 50.2$ & $200.4 \pm 63.2$ \\
\hline & After treatment & $131.9 \pm 34.4 \dagger$ & $122.9 \pm 31.6 \dagger$ \\
\hline & 1 month later & $175.4 \pm 49.7 *$ & $209.2 \pm 55.7$ \\
\hline
\end{tabular}

Data are presented as $M \pm \sigma$. To compare the values, the paired Student's t-test was used, $\dagger$ - differences compared to the initial level; * - compared to group 2, $p<0.05$. 
to control the training process. ${ }^{23}$ In addition to strength exercises, patients with osteoporotic VF also require coordination training, as they reduce the risk of falls, ${ }^{18,20}$ and of subsequent fractures. ${ }^{24}$ Therefore, in addition to physical exercises, training on special simulators in the form of stable and unstable platforms with an interactive element is used to improve coordination. Today's technologies make it possible to transfer rehabilitation into a virtual space, which combines well with sensorimotor training, since the centers responsible for maintaining balance activate during imaginary movement. $^{23}$

Based on the available information, we hypothesized that a rehabilitation program employing mechanotherapy methods with biofeedback for training trunk muscles and coordination, as well as special complexes of physiotherapy exercises in the gym and in the pool, in order to increase overall endurance, would be highly efficient in patients with osteoporotic VF. In patients with osteoporotic VF, all studied trunk muscle groups were $20-30 \%$ (9 kg, in absolute values) weaker than in patients with uncomplicated OP, which correlates with the literature data on the weakness of the muscle corset in patients with osteoporotic VF. ${ }^{25-26}$ In addition, patients with compression VF showed a tendency to pathological hyperflexion. Normally, trunk extension should prevail over flexion in a 3:2 ratio. However, in the main group, the ratio was $1: 1$. This phenomenon emphasizes the validity of training on special equipment aimed at training the deep stabilization system of the spine, and can also be considered as a point of application of rehabilitation measures. ${ }^{27}$ General weakening of the muscle strength and muscular corset, in particular, degenerative changes in bone tissue and joints, deformities of skeleton after fractures and formation of hyperkyphosis, impaired proprioceptive sensitivity and vestibular apparatus. All this leads to impaired coordination of motor abilities in patients with osteoporotic VF, ${ }^{28,29}$ which is also confirmed by our data. Indeed, our study shows that in patients who suffered osteoporotic VF, both dynamic and static balance are impaired, PC is displaced forward, not clearly localized and reaction time to changes in body position is slowed. Based on our data, after the rehabilitation strength of deep muscles of the back significantly increased and the muscle deficits in BE and TF were eliminated.

TE was affected the most, showing an average increase in strength by $6 \mathrm{~kg}$ (from 15.6 to $20.58 \mathrm{~kg}$ ), thereby eliminating more than a half of the muscle deficit (from $40.9 \%$ to $-15.9 \%)$. A comparable increase in strength occurred in the BF (on average $+4.5 \mathrm{~kg}$, from 14.6 to $19.1 \mathrm{~kg}$ ), which led to indicators even exceeding those recommended (muscle deficit was replenished from $18.1 \%$ to $+8.7 \%$ ). On average, the strength of the LLF and RLF muscles increased by $4.4 \mathrm{~kg}$.

The achieved effect was higher than in the control group and persisted for at least four weeks after end of rehabilitation, while in patients who received only gymnastic exercises, the strength indices returned to their initial values.

The positive effect of the rehabilitation program on the balance function in patients who had osteoporotic VF was confirmed. The center of gravity, which initially did not have clear contours and was significantly shifted forward, returned to the physiological position and became more localized. This proves the improvement of postural function and balance in standing position. In addition, the patient's response rate to changes in body position increased, which indicates improved coordination of movements and balance when walking. Thus, the new complex course of rehabilitation employing mechano- and kinesiotherapy, restored both static and dynamic balance functions in patients with osteoporotic VF.

The influence of the proposed rehabilitation complex on the coordination function of patients in the main group was significantly higher in comparison with the standard intervention (a set of physical exercises), and the achieved result persisted for at least a month after the end of therapy, which was not observed in the control group. As part of further research, it is possible to evaluate the rate and regularity with which the course should be repeated for optimal effect, as well as to investigate the effect of special physical rehabilitation complexes on the risk of falls and fractures in patients with OP. Implementation of rehabilitation programs aimed at training core muscles of the spine and balance function could improve medical care for patients with osteoporotic VF, reduce incapacity period and rehabilitation duration. A the three-week program of physical rehabilitation using mechanotherapy, balance therapy and special complexes of physiotherapy exercises in the gym and in the pool in patients with osteoporotic VFs significantly increases the strength of the muscle corset, helps to eliminate the existing muscle deficit in TE and TF and results in a more physiological distribution of the strength ratio between TE and TF. The rehabilitation program improves the function of static and dynamic balance, both with closed and open eyes, which can be observed in the return of the center of gravity to a more physiological position and in improved reaction speed to changes in body position.

The clinical effect achieved during the rehabilitation process persists for at least 4 weeks after the completion of therapy and depends on the initial values of vitamin D. Tensodinamometry and stabilometry can be successfully used to monitor the clinical effectiveness of rehabilitation courses in patients with VFs associated with OP.

In conclusion, provided that the rehabilitation measures are repeated and that the achieved effects are consolidated, the proposed complex of mechano- and kinesio-therapy can make a significant contribution to reducing the frequency of falls and associated fractures in elderly patients with OP by influencing important modifiable risk factors. 


\section{List of acronyms}

BFC - Balance function coefficient

BMD - Bone mass density

COBS -Coordination Balance Strength

FRAX - Fracture risk assessment tool

iOS app - application for iphone OS

LLF - left lateral flexors

OP -Osteoporosis

RLF - right lateral flexors

SKG - statokinesiogram

TE - trunk extensors

TF - trunk flexors

VF - vertebral fractures

\section{Contributions of Authors}

LM, idea and concept of the study, design; EM, study administration and article text; ME, bibliographical search and statistical analysis; AF, informational support; ES patient assessment and training; ECh patient assessment and training.

\section{Acknowledgments}

The Authors thank colleagues of the Department of Neurosciences, University of Padova, Italy and of the A\&C M-C Foundation for Translational Myology, Padova, Italy for discussions and critical readings.

\section{Funding}

None.

\section{Conflict of Interest}

The authors declare they have no financial, personal, or other conflicts of interest.

\section{Ethical Publication Statement}

We confirm that we have read the Journal's position on issues involved in ethical publication and affirm that this report is consistent with those guidelines.

\section{Corresponding Author}

Ekaterina Vladimirovna Makarova, N.A. Semashko National Research Institute of Public Health, 105064, st. Vorontsovo Pole 12, buiding 1, Moscow, Russia. Phone +79151114137

ORCID iD: 0000-0003-3767-8775

E-mail: rue-royal@inbox.ru

E-mails and ORCID iD of co-authors

Larisa A Marchenkova: Ir-march@rambler.ru ORCID iD: 0000-0003-1886-124X

Mikhail A Eryomushkin: medmassage@mail.ru

ORCID iD: 0000-0002-3452-870

AnatolyD Fesun: nmicrk@nmicrk.ru

ORCID iD: 0000-0003-3097-8889

Elena M Styazkina: styazelena@yandex.ru

ORCID iD: 0000-0003-4612-511

Ekaterina I Chesnikova: ekaterina-bokova@mail.ru ORCID iD: 0000-0002-2603-6170

\section{References}

1. Bliuc D, Nguyen ND, Milch VE, Nguyen TV, Eisman JA, Center JR. Mortality risk associated with low-trauma osteoporotic fracture and subsequent fracture in men and women. JAMA. 2009 Feb 4;301(5):513-21. doi: 10.1001/jama.2009.50.

2. Papaioannou A, Kennedy CC, Ioannidis G, Sawka A, Hopman WM, Pickard L, Brown JP, Josse RG, Kaiser S, Anastassiades T, Goltzman D, Papadimitropoulos M, Tenenhouse A, Prior JC, Olszynski WP, Adachi JD; CaMos Study Group. The impact of incident fractures on health-related quality of life: 5 years of data from the Canadian Multicentre Osteoporosis Study. Osteoporos Int. 2009 May;20(5):703-14. doi: 10.1007/s00198-0080743-7.

3. Kanis, J.A., Harvey, N.C., McCloskey, E. et al. Algorithm for the management of patients at low, high and very high risk of osteoporotic fractures. Osteoporos Int 31, 1-12 (2020). https://doi.org/10.1007/s00198-019-05176-3

4. Pfeifer M, Sinaki M, Geusens P, Boonen S, Preisinger E, Minne HW; ASBMR Working Group on Musculoskeletal Rehabilitation. Musculoskeletal rehabilitation in osteoporosis: a review. J Bone Miner Res. 2004 Aug;19(8):1208-14. doi: 10.1359/JBMR.040507.

5. WHO Scientific Group on the Burden of Musculoskeletal Conditions at the Start of the New Millennium. The burden of musculoskeletal conditions at the start of the new millennium. World Health Organ Tech Rep Ser. 2003;919:i-X, 1-218.

6. Weaver CM, Gordon CM, Janz KF, Kalkwarf HJ, Lappe JM, Lewis R, O'Karma M, Wallace TC, Zemel BS. The National Osteoporosis Foundation's position statement on peak bone mass development and lifestyle factors: a systematic review and implementation recommendations. Osteoporos Int. 2016 Apr;27(4):1281-1386. doi: 10.1007/s00198015-3440-3. Epub 2016 Feb 8. Erratum in: Osteoporos Int. 2016 Apr;27(4):1387.

7. Sinaki M. Exercise for patients with osteoporosis: management of vertebral compression fractures and trunk strengthening for fall prevention. PM R. 2012 Nov;4(11):882-8. doi: 10.1016/j.pmrj.2012.10.008.

8. Eryomushkin M.A. Physical activity and health. From therapeutic exercises to parkour. Moscow: Sport; 2016 (in russ.)

9. Parreira PCS, Maher CG, Megale RZ, March L, Ferreira ML. An overview of clinical guidelines for the management of vertebral compression fracture: a systematic review. Spine J. 2017 Dec;17(12):1932-1938. doi: 10.1016/j.spinee.2017.07.174.

10. Genant HK, Jergas M, Palermo L, Nevitt M, Valentin RS, Black D, Cummings SR. Comparison of semiquantitative visual and quantitative 
morphometric assessment of prevalent and incident vertebral fractures in osteoporosis The Study of Osteoporotic Fractures Research Group., Journal of Bone and Mineral Research.1996;11:984-996.

11. White Book on Physical and Rehabilitation Medicine in Europe. Introduction, Executive Summary and Methodology. Eur J Rehabil Med. 2018: 54(2): 125 - 155

12. Razi AE, Hershman HS, Stuart H (Eds.). Vertebral Compression Fractures in Osteoporotic and Pathologic Bone: A Clinical Guide to Diagnosis and Management. Springer. 1st ed. 2020. 244 p. ISBN10: 3030338606

13. Lesnyak OM. Osteoporosis. Brief guidelines for doctors. GEOTAR-Media, 2019. 224 p. (in russ.)

14. Camacho PM, Petak SM, Binkley N, Diab DL, Eldeiry LS, Farooki A, Harris ST, Hurley DL, Kelly J, Lewiecki EM, Pessah-Pollack R, McClung M, Wimalawansa SJ, Watts NB. American association of clinical endocrinologists/american college of endocrinology Clinical practice guidelines for the diagnosis and treatment of postmenopausal osteoporosis - 2020 Update executive summary. Endocr Pract. 2020 May;26(5):564-570. doi: 10.4158/GL-2020-0524.

15. Scottish Intercollegiate Guidelines Network. Management of osteoporosis and the prevention of fragility fractures. Revised edition published June 2020. Avaliable

https://www.sign.ac.uk/assets/sign50_2019.pdf

16. Tarantino U, Iolascon G, Cianferotti L, Masi L, Marcucci G, Giusti F, Marini F, Parri S, Feola M, Rao C, Piccirilli E, Zanetti EB, Cittadini N, Alvaro R, Moretti A, Calafiore D, Toro G, Gimigliano F, Resmini G, Brandi ML. Clinical guidelines for the prevention and treatment of osteoporosis: summary statements and recommendations from the Italian Society for Orthopaedics and Traumatology. J Orthop Traumatol. 2017 Nov;18(Suppl 1):3-36. doi:10.1007/s10195-017-0474-7.

17. Sveshnikov A.A. Skeletal bone mineral density, muscle mass and fracture prevention problems. Moscow: Publishing House of the Academy of Natural Sciences.2013.366 p. (in russ.)

18. Callréus M, McGuigan F, Ringsberg K, Åkesson K. Self-reported recreational exercise combining regularity and impact is necessary to maximize bone mineral density in young adult women : A population-based study of 1,061 women 25 years of age. Osteoporosis International. 2012;23(10):25172526. https://doi.org/10.1007/s00198-011-1886-5

19. Braun SI, Kim Y, Jetton AE, Kang M, Morgan DW. Sedentary Behavior, Physical Activity, and Bone Health in Postmenopausal Women. J Aging Phys Act. 2017 Apr;25(2):173-181. doi: 10.1123/japa.2016-0046.

20. Gerasimenko MYu, Eremushkin MA, Arkhipov MV, Kolyagin YuI, Antonovich IV Prospects for the development of robotic manipulation mechanotherapy complexes. Physiotherapy, balneology and rehabilitation. 2017; 2: 65-69.

21. World Health Organization. (WHO global report on falls prevention in older age. Geneva: World Health Organization, 2008. Available at https://apps.who.int/iris/handle/10665/43811

22. Madureira MM, Takayama L, Gallinaro AL, Caparbo VF, Costa RA, Pereira RM. Balance training program is highly effective in improving functional status and reducing the risk of falls in elderly women with osteoporosis: a randomized controlled trial. Osteoporos Int. 2007 Apr; 18(4):419-25. doi: 10.1007/s00198-006-0252-5.

23. Hongo M, Itoi E, Sinaki M, Miyakoshi N, Shimada Y, Maekawa S, Okada K, Mizutani Y. Effect of low-intensity back exercise on quality of life and back extensor strength in patients with osteoporosis: a randomized controlled trial. Osteoporos Int. 2007 Oct;18(10):1389-95. doi: 10.1007/s00198-007-0398-9.

24. McGrath RP, Kraemer WJ, Vincent BM, Hall OT, Peterson MD. Muscle Strength Is Protective Against Osteoporosis in an Ethnically Diverse Sample of Adults. J Strength Cond Res. 2017 Sep;31(9):2586-2589.

doi: 10.1519/JSC.0000000000002080.

25. Moreira LDF, de Oliveira ML, Lirani-Galvão AP, Marin-Mio RV, dos Santos RN, Lazaretti-Castro M. Physical exercise and osteoporosis: effects of different types of exercises on bone and physical function of postmenopausal women. Arq Bras Endocrinol Metab. 2014; 58(5): 514-522. http://dx.doi.org/10.1590/0004-2730000003374.

26. Ioannidis G, Papaioannou A, Hopman WM, Akhtar-Danesh N, Anastassiades T, Pickard L, Kennedy CC, Prior JC, Olszynski WP, Davison KS, Goltzman D, Thabane L, Gafni A, Papadimitropoulos EA, Brown JP, Josse RG, Hanley DA, Adachi JD. Relation between fractures and mortality: results from the Canadian Multicentre Osteoporosis Study. CMAJ. 2009 Sep 1;181(5):265-71. doi: 10.1503/cmaj.081720.

27. Makarova EV, Marchenkova LA, Eryomushkin MA, Styazkina EM, Chesnikova EI. Balance and muscle strength tests in patients with osteoporotic vertebral fractures to develop tailored rehabilitation programs. Eur J Transl Myol. 2020 Sep 9;30(3):9236. doi: 10.4081/ejtm.2020.9236.

28. Burke TN, França FJ, Ferreira de Meneses SR, Cardoso VI, Marques AP. Postural control in elderly persons with osteoporosis: Efficacy of an intervention program to improve balance and muscle strength: a randomized controlled trial. Am J Phys Med Rehabil. 2010 Jul;89(7):549-56. doi: 10.1097/PHM.0b013e3181ddccd2.

29. Howe TE, Shea B, Dawson LJ, Downie F, Murray A, Ross C, Harbour RT, Caldwell LM, Creed G. 


\section{Rehabilitation after osteoporotic vertebral fractures}

Eur J Transl Myol 31 (4): 9945, 2021 doi: 10.4081/ejtm.2021.9945

Exercise for preventing and treating osteoporosis in postmenopausal women. Cochrane Database Syst Rev. 2011 Jul 6;(7):CD000333. doi: 10.1002/14651858.CD000333.pub2.

Submission: June 30, 2020

Revision submitted: September 22, 2021 Accepted for publication: September 22, 2021 